\title{
SIMULTANEOUS DETERMINATION OF DRUGS USED FOR CHRONIC ACTIVE GASTRITIS DISEASE BY CHEMOMETRIC METHODS
}

Guzide Pekcan Ertokus ${ }^{1}$, Kazım Bagracık ${ }^{2}$

Abstract- The spectrophotometric-chemometric analysis of clarithromycin amoxicillin and lansoprazole that are used for the eradication of Helicobacter pylori (HP) was analysis without any prior reservation. The used chemometric methods were principal component regression (PCR) and partial least squares regression (PLSR). In the first step, the synthetic mixtures including clarithromycin, amoxicillin and lansoprazole were prepared and absorbance values are obtained from spectrophotometry. Absorbance and concentration values were used in Minitab and other chemometric programs to calculate estimated concentrations with PCR and PLSR. Because of recovery and standard deviation were accomplished, this study encouraged us to applied for drug analysis. The second step, in drug tablets was calculated clarithromycin, amoxicillin and lansoprazole amounts.

Keywords - clarithromycin, amoxicillin, lansoprazole, PLSR, PCR.

\section{INTRODUCTION}

Clarithromycin [1], amoxicillin [2] and lansoprazole [3] are used for eradication of gastrointestinal system infection with Helicobacter pylori (HP) [4]. Helicobacter pylori (HP), a gram-negative bacterium incorporated with gastritis and different types of ulcers [5]. When Helicobacter pylori (HP) is not treated, development of gastric cancer allows [6,7]. Therefore, eradication of Helicobacter pylori (HP) is important from healty life style [8,9]. Eradication of Helicobacter pylori (HP) is used consisting of a combination with two different antibiotics together with a protonpumb innibitor as antisecretory agent $[10,11]$. Chemometric calibration methods are observed that it is the best techniques to determinate the amount of each component in the complex mixture. The most accepted chemometric methods in drug analysis are principal component regression (PCR) and partial least squares regression (PLSR) $[12,13]$. A relationship to be established between matrices of chemical data is determinated at chemometric methods [14]. Clarithromycin , amoxicillin and lansoprazole is determinated with spectrophotometry $[15,16,17]$ and HPLC method [14].

In this study, principal component regression (PCR) and partial least squares regression (PLSR) were successfully performed to simultaneous determination of clarithromycin, amoxicillin and lansoprazole in a commercial tablet formulation, tablets without any separation method. Mean recoveries (\%) and standard deviation of principal component regression (PCR) and partial least squares regression (PLSR) methods were calculated for the validation of the methods. The acquired results were statistically compared each other.

\section{Chemometric Method}

Partial least squares regression (PLS-regression) is the most commonly used chemometric multivariate calibration method [18]. PLS is done using both experimental (or $\mathrm{x}$ ) and concentration (or c) data simultaneously. Usually PLS is presented in the form of equations. There are a few ways to express them, the most suitable for our purpose being:

$$
\begin{aligned}
\mathrm{X}= & \mathrm{T} . \mathrm{P} .+\mathrm{E} \\
& (1) \\
\mathrm{c}= & \mathrm{T} . \mathrm{q}+\mathrm{f}
\end{aligned}
$$

Where $\mathrm{X}$ refers to the experimental measurements (e.g. spectra) and $\mathrm{c}$ is the concentration. There is a correlation with an installation for vector vector $\mathrm{q}$. Matrix $\mathrm{T}$ is common to both equations. $\mathrm{E}$ is an error matrix and error to prevent the $\mathrm{x}$ vector $\mathrm{c}$ to block scores f orthogonal, but non-orthogonal (P) loads, generally are non-normalized [19]. The Minitab 17 program (Inova, Ankara, Turkey) was used for the analysis of all the concentration and absorbance data and to do the statistical calculations. Minitab is a statistical analysis software. In addition to statistical research, statistics can be used to learn [20].

\footnotetext{
${ }^{1}$ Department of Chemistry, Faculty of Science \& Art, Süleyman Demirel University, Isparta, Turkey,

${ }^{2}$ Department of Chemistry, Faculty of Science \& Art, Süleyman Demirel University, Isparta, Turkey
} 


\section{EXPERIMENT AND RESULT}

All materials used were analytical grade. Stock solutions of $25 \mathrm{mg} / 250 \mathrm{~mL}$ of clarithromycin (Sigma), amoxicillin (Sigma) and lansoprazole (Sigma) were prepared with $0.1 \mathrm{M} \mathrm{HCl}$. A training set and validation set containing the drugs in various proportions, 25 synthetic mixtures synthetic mixtures (for validation) was made. Low conductivity water $(0.05 \mathrm{~S} / \mathrm{cm})$ was obtained using Millipore's Milli-Q Integral lab water purification system. A Shimadzu UV1700 PharmaSpec Spectrophotometer connected to an IBM PS with UV Probe Software was used for all measurements and data processing. A pair of $1.0 \mathrm{~cm}$ quartz cuvettes were used for absorbance measurements.

\section{Absorbance Measurements}

Absorbance spectra, clarithromycin amoxicillin and lansoprazole both points and the corresponding spaces between contrasting with the 0,1 range $200-350 \mathrm{~nm}$ were recorded. The calibration matrix and training and validation sets contain three component mixtures, at different rates and optimized, and the resulting spectra analysis and analysis of real samples to calculate concentrations have been calculated using PLSR and PCR. Samples of 4.0 and 40.00 $(\mu \mathrm{g} / \mathrm{ml})$ between drugs (alone or in combination) were placed in volumetric flasks, $25 \mathrm{~mL}$ and an aliquot containing $0.1 \mathrm{M} \mathrm{HCl}$ was added. The mixture was shaken for 20 minutes and filtered. Dry tight standards were prepared in the same manner as described except those with the reagents and drug. The concentrations prepared from clarithromycin amoxicillin and lansoprazole for the PLSR and PCR calibrations are listed in Table 1.

Table 1. Concentration Set for clarithromycin amoxicillin and lansoprazole

\begin{tabular}{|c|c|c|c|}
\hline & \multicolumn{3}{|c|}{ Concentration(ppm) } \\
\hline NO & Clarithromycin & Amoxicillin & Lansoprazole \\
\hline 1 & 6 & 8 & 4 \\
\hline 2 & 6 & 16 & 12 \\
\hline 3 & 6 & 24 & 20 \\
\hline 4 & 6 & 32 & 28 \\
\hline 5 & 6 & 40 & 36 \\
\hline 6 & 12 & 8 & 4 \\
\hline 7 & 12 & 16 & 12 \\
\hline 8 & 12 & 24 & 20 \\
\hline 9 & 12 & 32 & 28 \\
\hline 10 & 12 & 40 & 36 \\
\hline 11 & 18 & 8 & 4 \\
\hline 12 & 18 & 16 & 12 \\
\hline 13 & 18 & 24 & 20 \\
\hline 14 & 18 & 32 & 28 \\
\hline 15 & 18 & 40 & 36 \\
\hline 16 & 24 & 8 & 4 \\
\hline 17 & 24 & 16 & 12 \\
\hline 18 & 24 & 24 & 20 \\
\hline 19 & 24 & 32 & 28 \\
\hline 20 & 24 & 40 & 36 \\
\hline 21 & 30 & 8 & 4 \\
\hline 22 & 30 & 16 & 12 \\
\hline 23 & 30 & 24 & 20 \\
\hline 24 & 30 & 32 & 28 \\
\hline 25 & 30 & 40 & 36 \\
\hline & & & \\
\hline
\end{tabular}

\section{Pharmaceutical Preparations}

A commercial drug preparations; Helipak ( ${ }^{\circledR}$ tablet produced by Fako Pharm. In. Turkey, containing $500 \mathrm{mg}$ clarithromycin, $1000 \mathrm{mg}$ amoxicillin, $30 \mathrm{mg}$ lansoprazole, per tablet were analyzed by principal component regression (PCR) and partial least squares regression (PLSR) chemometric methods.

For this purpose $20 \mathrm{~mL}$ samples of drugs were transferred into $25 \mathrm{~mL}$ bottles and mechanically mixed into $0.1 \mathrm{M}$ $\mathrm{HCl}$. All the techniques were applied to the final solution.

Clarithromycin, amoxicillin and lansoprazole are all in the visible region of high absorbent substances. Figure 1 shows the absorbance-wavelength $(\mathrm{nm})$ curves. The spectrum of Clarithromycin, amoxicillin and lansoprazole are in the range of 200-350 nm. 


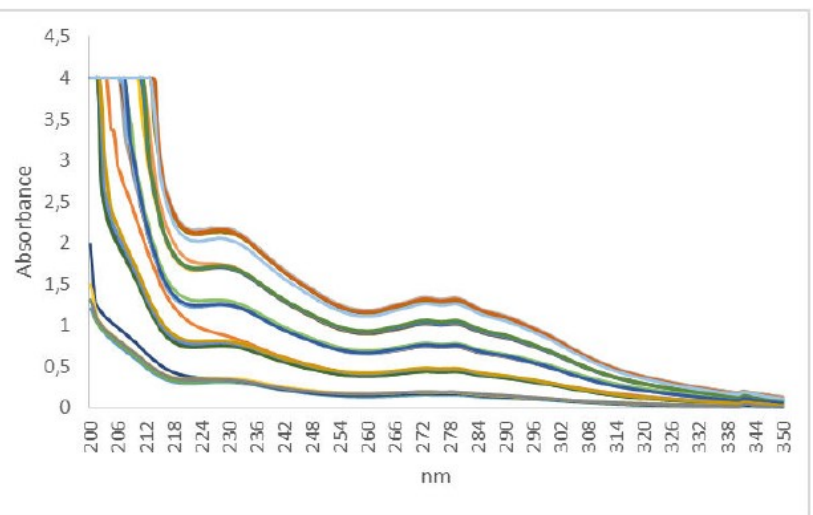

Figure 1. The spectrum of Clarithromycin, amoxicillin and lansoprazole mixtures.

Figure1 shows absorption spectra for clarithromycin, amoxicillin and lansoprazole mixtures in $0.1 \mathrm{M} \mathrm{HCl}$.

Our objective in this study is to develop a lower-cost but more quick and reliable analytical method using chemometry. With this method, active ingredients can be analyzed without pre-separation, and loss of time and work due to the trial and error method will be prevented.

The PLSR method and absorption spectra can be used individually or overlapping for multiple simultaneous detection of very linear components. Some statistical parameters were given for validation of calibrations for synthetic mixtures of drugs.

Table 2. Composition of prediction set and recovery results obtained in synthetic mixtures for PLSR method.

\begin{tabular}{|c|c|c|c|c|c|c|c|c|}
\hline \multicolumn{3}{|c|}{ Actual Concentration (ppm) } & \multicolumn{3}{|c|}{ Prediction Concentration (ppm) } & \multicolumn{3}{|c|}{ Recovery $(\%)$} \\
\hline Clarithromycin & Amoxicillin & Lansoprazole & Clarithromycin & Amoxicillin & Lansoprazole & Clarithromycin & Amoxicillin & Lansoprazole \\
\hline 6 & 8 & 4 & 5.99 & 8.11 & 3.88 & 98.83 & 101.38 & 97.00 \\
\hline 6 & 16 & 12 & 5.89 & 16.19 & 12.28 & 98.17 & 101.19 & 102.33 \\
\hline 6 & 24 & 20 & 5.91 & 23.56 & 19.86 & 98.50 & 98.17 & 99.30 \\
\hline 6 & 32 & 28 & 6.04 & 31.14 & 28.17 & 100.67 & 97.31 & 100.61 \\
\hline 6 & 40 & 36 & 5.99 & 39.71 & 36.12 & 99.83 & 99.28 & 100.33 \\
\hline 12 & 8 & 4 & 11.78 & 8.31 & 4.04 & 98.17 & 103.88 & 101.00 \\
\hline 12 & 16 & 12 & 11.65 & 16.46 & 12.32 & 97.08 & 102.88 & 102.67 \\
\hline 12 & 24 & 20 & 12.27 & 24.14 & 19.63 & 102.25 & 100.58 & 98.15 \\
\hline 12 & 32 & 28 & 11.63 & 32.39 & 28.13 & 96.92 & 101.22 & 100.46 \\
\hline 12 & 40 & 36 & 11.99 & 40.13 & 36.04 & 99.92 & 100.33 & 100.11 \\
\hline 18 & 8 & 4 & 18.46 & 7.64 & 3.85 & 102.56 & 95.50 & 96.25 \\
\hline 18 & 16 & 12 & 18.42 & 16.00 & 11.89 & 102.33 & 100.00 & 99.08 \\
\hline 18 & 24 & 20 & 18.17 & 24.22 & 20.07 & 100.94 & 100.92 & 100.35 \\
\hline 18 & 32 & 28 & 18.32 & 31.83 & 27.81 & 101.78 & 99.47 & 99.32 \\
\hline 18 & 40 & 36 & 18.40 & 40.27 & 35.43 & 102.22 & 100.68 & 98.42 \\
\hline 24 & 8 & 4 & 24.02 & 8.18 & 4.09 & 100.08 & 102.25 & 102.25 \\
\hline 24 & 16 & 12 & 24.02 & 16.2 & 12.02 & 100.08 & 101.25 & 100.17 \\
\hline 24 & 24 & 20 & 24.74 & 24.27 & 20.08 & 103.08 & 101.13 & 100.40 \\
\hline 24 & 32 & 28 & 24.75 & 32.21 & 28.99 & 103.13 & 100.66 & 103.54 \\
\hline 24 & 40 & 36 & 23.82 & 40.42 & 35.7 & 99.25 & 101.05 & 99.17 \\
\hline 30 & 8 & 4 & 30.33 & 7.93 & 3.88 & 101.10 & 99.13 & 97.00 \\
\hline 30 & 16 & 12 & 30.43 & 16.82 & 12.07 & 101.43 & 105.13 & 100.58 \\
\hline 30 & 24 & 20 & 29.98 & 24.12 & 20.15 & 99.93 & 100.50 & 100.75 \\
\hline 30 & 32 & 28 & 29.82 & 32.11 & 28.03 & 99.40 & 100.34 & 100.11 \\
\hline 30 & 40 & 36 & 28.74 & 40.01 & 36.01 & 95.80 & 100.03 & 100.03 \\
\hline & & & & & & $\begin{array}{c}\text { Mean }: 100.18 \\
\text { Standard } \\
\text { Deviation:1.98 }\end{array}$ & $\begin{array}{c}\text { Mean }: 100.57 \\
\text { Standard } \\
\text { Deviation:1.94 }\end{array}$ & $\begin{array}{c}\text { Mean:99.97 } \\
\text { Standard } \\
\text { Deviation:1.75 }\end{array}$ \\
\hline
\end{tabular}

Table 3. Composition of prediction set and recovery results obtained in synthetic mixtures for PCR method.

\begin{tabular}{|c|c|c|c|c|c|c|c|c|}
\hline \multicolumn{3}{|c|}{ Actual Concentration (ppm) } & \multicolumn{2}{c|}{ Prediction Concentration (ppm) } & \multicolumn{3}{c|}{ Recovery (\%) } \\
\hline Clarithromycin & Amoxicillin & Lansoprazole & Clarithromycin & Amoxicillin & Lansoprazole & Clarithromycin & Amoxicillin & Lansoprazole \\
\hline 6 & 8 & 4 & 5.86 & 8.01 & 4.01 & 97.67 & 100.12 & 100.25 \\
\hline 6 & 16 & 12 & 5.78 & 15.95 & 11.96 & 96.33 & 99.69 & 99.67 \\
\hline 6 & 24 & 20 & 5.81 & 24.01 & 20.01 & 96.83 & 100.04 & 100.05 \\
\hline 6 & 32 & 28 & 6.04 & 31.86 & 27.89 & 100.67 & 99.56 & 99.61 \\
\hline 6 & 40 & 36 & 6.02 & 39.52 & 36.01 & 100.33 & 98.80 & 100.03 \\
\hline 12 & 8 & 4 & 11.77 & 8.02 & 3.96 & 98.08 & 100.25 & 99.00 \\
\hline 12 & 16 & 12 & 11.6 & 15.96 & 11.96 & 96.67 & 99.75 & 99.67 \\
\hline 12 & 24 & 20 & 11.75 & 23.95 & 19.98 & 97.92 & 99.79 & 99.90 \\
\hline 12 & 32 & 28 & 11.63 & 32.01 & 27.96 & 96.92 & 100.03 & 99.86 \\
\hline 12 & 40 & 36 & 11.96 & 39.96 & 35.94 & 99.67 & 99.90 & 99.83 \\
\hline 18 & 8 & 4 & 17.78 & 7.96 & 4.01 & 98.78 & 99.50 & 100.25 \\
\hline 18 & 16 & 12 & 17.85 & 15.95 & 11.96 & 99.17 & 99.69 & 99.67 \\
\hline 18 & 24 & 20 & 17.76 & 24.01 & 19.95 & 98.67 & 100.04 & 99.75 \\
\hline 18 & 32 & 28 & 18.23 & 31.98 & 27.96 & 101.28 & 99.94 & 99.86 \\
\hline
\end{tabular}




\begin{tabular}{|c|c|c|c|c|c|c|c|c|}
\hline 18 & 40 & 36 & 18.42 & 39.98 & 35.96 & 102.33 & 99.95 & 99.89 \\
\hline 24 & 8 & 4 & 24.01 & 7.85 & 3.95 & 100.04 & 98.13 & 98.75 \\
\hline 24 & 16 & 12 & 23.96 & 15.96 & 11.95 & 99.83 & 99.75 & 99.58 \\
\hline 24 & 24 & 20 & 23.86 & 24.01 & 19.96 & 99.42 & 100.04 & 99.80 \\
\hline 24 & 32 & 28 & 23.95 & 32.21 & 27.96 & 99.79 & 100.66 & 99.86 \\
\hline 24 & 40 & 36 & 24.02 & 39.95 & 35.96 & 100.08 & 99.88 & 99.89 \\
\hline 30 & 8 & 4 & 29.69 & 7.94 & 3.96 & $\begin{array}{l}98.97 \\
\end{array}$ & 99.25 & 99.00 \\
\hline 30 & 16 & 12 & 29.75 & 15.96 & 11.96 & 99.17 & 99.75 & 99.67 \\
\hline 30 & 24 & 20 & 29.85 & 23.95 & 19.95 & 99.50 & 99.79 & 99.75 \\
\hline 30 & 32 & 28 & 30.01 & 31.95 & 27.89 & 100.03 & 99.84 & 99.61 \\
\hline 30 & 40 & 36 & 30.02 & 39.94 & 35.94 & 100.07 & 99.85 & 99.83 \\
\hline & & & & & & $\begin{array}{c}\text { Mean :99.13 } \\
\text { Standard } \\
\text { Deviation:1.48 }\end{array}$ & $\begin{array}{c}\text { Mean :99.76 } \\
\text { Standard } \\
\text { Deviation:0.48 }\end{array}$ & $\begin{array}{c}\text { Mean:99.72 } \\
\text { Standard } \\
\text { Deviation:0.35 }\end{array}$ \\
\hline
\end{tabular}

This study, the statistical parameters were found to produce a satisfactory validity for the PLSR and PCR methods. The PLSR and PCR methods have reliable accuracy and higher precision. For calibration the prediction residual error sum-of-squares (PRESS) was calculated as:

$$
\text { PRESS }=\sum_{i=1}^{n}\left(C_{i}^{\text {added }}-C_{i}^{\text {found }}\right)^{2}
$$

$\mathrm{C}_{\mathrm{i}}^{\text {added }}$ : Actual Concentration, the added concentration of drug.

$\mathrm{C}_{\mathrm{i}}^{\text {added }}$ : Predicted Concentration, the calculated concentration of drug.

The RMSEC can provide a good measure of how well, on average, the calibration model performs. According to the actual and predicted concentrations of the samples, RMSEC and PRESS values of clarithromycin, amoxicillin and lansoprazole were calculated and listed in Table 2.

The root mean square error of cross-validation/RMSEC was calculated for each method as follows:

$$
\mathrm{RMSEC}=(\mathrm{PRESS} / \mathrm{n})^{1 / 2}
$$

$\mathrm{n}$ : the number of predicted samples

Some statistical parameters determined the effectiveness of the calibration. The standard error of prediction

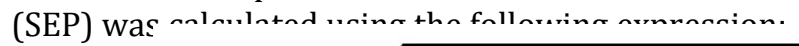

$$
S E P=\sqrt{\frac{\sum_{i=1}^{n}\left(C_{i}^{\text {added }}-C_{i}^{\text {found }}\right)^{2}}{n-1}}
$$

$\mathrm{C}_{\mathrm{i}}^{\text {added }}$ : Actual Concentration, the added concentration of drug

$\mathrm{C}_{\mathrm{i}}{ }^{\text {added }}$ : Predicted Concentration, the calculated concentration of drug

$\mathrm{n}$ : the total number of synthetic mixtures

Table 3. Statistical parameter values for calibration step- simultaneous determination of clarithromycin, amoxicillin and lansoprazole using partial least square and principal component regression methods.

\begin{tabular}{|c|c|c|c|c|}
\hline Parameter & Method & \multicolumn{3}{|c|}{ Compound } \\
\cline { 3 - 5 } & & Clarithromycin & Amoxicillin & Lansoprazole \\
\hline RMSEC & PLSR & 0.096 & 0.069 & 0.055 \\
& PCR & 0.042 & 0.024 & 0.010 \\
\hline PRESS & PLSR & 0.230 & 0.120 & 0.075 \\
& PCR & 0.045 & 0.014 & 0.0025 \\
\hline SEP & PLSR & 0.110 & 0.090 & 0.060 \\
& PCR & 0.06 & 0.023 & 0.014 \\
\hline
\end{tabular}

Analysis of pharmaceutical formulation (mg/tablet)

Table 4. lists the experimental results of the two numerical methods for pharmaceutical formulation and as you can see the obtained results are very close to each other. 
Table 4. Determination of clarithromycin, amoxicillin and lansoprazole in pharmaceutical formulation using PLSR and PCR methods.

\begin{tabular}{|c|c|c|c|c|c|c|}
\hline No & \multicolumn{3}{|c|}{ PLSR } & \multicolumn{3}{c|}{ PCR } \\
\hline & Clarithromycin & Amoxicillin & Lansoprazole & Clarithromycin & Amoxicillin & Lansoprazole \\
\hline $\mathbf{1}$ & 0.450 & 0.872 & 0.027 & 0.442 & 0.986 & 0.028 \\
\hline $\mathbf{2}$ & 0.300 & 0.942 & 0.031 & 0.456 & 0.889 & 0.023 \\
\hline $\mathbf{3}$ & 0.486 & 0.932 & 0.023 & 0.372 & 0.923 & 0.025 \\
\hline Mean & 0.412 & 0.915 & 0.027 & 0.423 & 0.933 & 0.025 \\
\hline $\begin{array}{l}\text { Standard } \\
\text { Deviation }\end{array}$ & 0.097 & 0.038 & 0.004 & 0.045 & 0.049 & 0.003 \\
\hline
\end{tabular}

In this study, chemometric methods based on spectral data processing, clarithromycin, amoxicillin and lansoprazol, without interference in each other's mixes and beverages containing a ternary mixture of the two can be applied for simultaneous identification.

In order to compare the performances of the investigated chemometric techniques according to UV spectrophotometric method for real samples we applied Snedecor's $F$-test.

The method used to compare the differences between the one-way ANOVA test was applied to the actual samples for each food drug. In this study, Snedecor's F-values were calculated and compared with the $F$ value . The same computation process was repeated for each drugs. In table 5 shows ANOVA results.. The experimental (calculated) $F$-values did not exceed the $F$-value in the variance analysis. Among all these methods, it was concluded that there was a meaningful difference. All statistical parameters and numeric values are suitable for simultaneous identification in the actual samples.

Table 5. The Results of the one-way ANOVA test (PLSR and PCR)

\begin{tabular}{|c|c|c|c|c|c|c|c|}
\hline & & \multicolumn{3}{|c|}{$\mathrm{F}_{\text {calculated }}$ PLSR } & \multicolumn{3}{|c|}{$F_{\text {critical }}-$ PLSR } \\
\hline & & Clarithromycin & Amoxicillin & Lansoprazole & Clarithromycin & Amoxicillin & Lansoprazole \\
\hline $\begin{array}{c}\text { Between } \\
\text { groups }\end{array}$ & 1 & 0.000646 & 0.000845 & $4.38 \mathrm{E}-05$ & & 4.042652 & \\
\hline $\begin{array}{l}\text { Within } \\
\text { groups }\end{array}$ & 48 & & & & & & \\
\hline Total & 49 & & & & & & \\
\hline & & & calculated_PCR & & & $\mathrm{F}_{\text {critical }} \mathrm{PCR}$ & \\
\hline $\begin{array}{c}\text { Between } \\
\text { groups }\end{array}$ & 1 & 0.001826 & 0.000199 & 0.00015 & & 4.042652 & \\
\hline $\begin{array}{l}\text { Within } \\
\text { groups }\end{array}$ & 48 & & & & & & \\
\hline Total & 49 & & & & & & \\
\hline
\end{tabular}

\section{IV.CONCLUSION}

The partial least squares method and principle component regression all successfully applied at the same time were able to identify drugs in synthetic solutions and pharmaceutical formulation. For all values, low prediction errors and high correlation coefficients emphasize the high linear relationship between the predicted and actual concentrations. The results obtained with this ternary mixture and some ratios of component concentrations show excellent predictive ability with these methods.

\section{ACKNOWLEDGEMENT}

This research work has been supported by research grants from Süleyman Demirel University Scientific Research Project 4623-YL1-16.

\section{REFERENCES}

[1] Uygun, A. Kadayıfçı, Z. Yeşilova, M.C. Savaş, Y. Ateş, Y. Karslığlu, M. Ciğerim, S. Bağcı, K. Dağalp, “ Recent success of pantoprazole -or lansoprazole- based clarithromycin plus amoxicillin treatment in the eradication of Helicobacter pylori ", Turk J. Gastroenterol, vol. 4, pp. 219-224, 2004

[2] M. Horoz, C. Bölükbaş, F.F. Bölükbaş, A. Uzunköy, A. Soylu, "Klaritromisin-Amoksisilin-Lansoprazol Kombinasyonunda Optimal Tedavi Süresi, HrÜ. Tip Fak. Der., vol. 1, pp. 12-19, 2004.

[3] A Uygun, A. Tüzün, Z. Yeşilova, M. Aslan, Y. Ateş, Z. Polat, A. Erdil, S. Bağcı, Ö. Günhan, M. Gülşen, K. Dağalp, "Helicobacter pylori eradikasyon tedavisinde 7 ve 14 günlük lansoprazol, amoksisiln, klaritromisin protokolünün karşılaştırılması", Akademik Gastroentreroji Dergisi, vol. 4-3, pp.172-175, 2005.

[4] M. M. Elkhoudary, R. A. A. Salam, G. M. Hadad, "Robustness testing in HPLC analysis of clarithromycin, norfloxacin, doxycycline, tinidazole and omeprazole in pharmaceutical dosage forms using experimantal design", Current Pharmaceutical Analysis, vol, 10. pp. 5870,2005 . 
[5] A. Sameh, N.N. Atia, "Simultaneous determination of triple therapy for Helicobacter pylori in human plasma by reversed phase chromatography with online wavelength switching", Spectrochimica Acta Part A: Molecular and biomolecular spectroscopy, vol. 136, pp. $1380-1387,2015$

[6] D.Y. Graham, "Treatment of peptic ulcers caused by Helicobacter pylori”, N. Engl. J. Med., vol. 328, pp. 349-350. 1993.

[7] S.V. Zanten, P. Sherman, "Indications for the treatment of Helicobacter pylori: a systematic overview, Can.Med. Ass J., vol. 150, pp. 177$185,1994$.

[8] P. Lulie, D.F. Gary, P. Daniel, Y.C. Vandersteen, H. Joseph, D.E.E. Vogelman, O. Norman, K.S. Richard, "Helicobacter pylori infection and the risk of gastric carcinoma", N. Engl. J. Med., vol. 325, pp. 1127-1131, 1991.

[9] F.C. Ramirez, G. Lew, P.D. Klein, R.M. Genta, D.Y. Graham, "Search for improved anti- Helicobacter pyloritherapies", Am. J. Gastroenterol, vol. 87, pp. 1275-1279, 1992.

[10] N. Vakil, "The montreal definition and classification of gastroesophageal reflux disease: a global evidence-based consensus", Am. J. Gastroenterol, vol. 8, pp. 1900-1920, 2006.

[11] I. Satoshi, M. Fukuto, S. Kazufumi, M. Shinichi, T. Masahiko, K. Kiyomi, O. Kozue, H. Mayayoshi, K. Yoshiyuki, O. Hitoyoshi, "In vivo bactericidal activities oj Japanase rice-fluid against H. Pylori in a Mongolian gerbil model, Int. J. Med. Sci. vol. 4, pp. 203-208, 2007.

[12] E. Dinç, D. Baleanu, "Spectrophotometric quantitative determination of cilazapril and hydrochlorothiazide in tablets by chemometric methods" Journal of pharmaceutical abn biomedical analysis, vol.30, pp. 715-723, 2002.

[13] E. Dinç,A. Özdemir, D. Baleanu, "Comparative study of the continuous wavelent transform, derivative and partial least squares methods applied to the overlapping spectra for the simultaneous quantitative resolution of ascorbic acid and asetilsalicylic acid in effervescent tablets Journal of pharmaceutical abn biomedical analysis, vol.37, pp. 715-723, 2005.

[14] A.H. Aktaş, A.M. Sarıdağ, "Liquid chromatografic-chemometric tecnhniques for the simultaneous HPLC determination of lansoprazole, amoksisilin and clarithromisin in commerciaal preparation", Journal of chromatografic science, pp. 1-7, 2017.

[15] A.H. Aktaş, H.H. Toprak, "Spectrometric determination of lansoprazole and domperidone in tablets by multivariate calibration approach", Journal of chemical and pharmaceutical research, vol.9(3), pp.103-108.

[16] H.M. Lofty, S. M. Tawakkol, N.M. Fahmy, M.A. Shehata, " A Comparative study of novel spectrophorometric resolution techniques applied for pharmaceutical mixtures with partially or severely overlapped spectra", Spectrochimica acta part A: Molecular and Biomolecular cpectroscopy, vol. 136, pp. 937-952, 2015.

[17] H.A. Merey, N.K. Ramadan, S.S. Diab, A.A. Moustafa, "Spectrophotometric methods for simultaneous determination of ternary mixture of amplodipine besylate, olmesartan medoxomil and hydrochlorothiazide", Spectrochimica acta part A: Molecular and Biomolecular cpectroscopy, vol. 125, pp. 138-146, 2014.

[18] Kenneth R.B., Chemometrics: A practical guide, John Wiley \& Sons. Inc., New York, 1998.

[19] Brereton R.C., Applied Chemometrics for Scientists, John Wiley \& Sons. Inc., New York, 2007.

[20] http://www.causeweb.org/repository/Minitab/Minitab.pdf. (17.05.2017) 